\title{
Racial Animosity and Black Financial Advisor Underrepresentation
}

\author{
Jeffrey A. DiBartolomeo ${ }^{a}$ \\ Michael G. Kothakota ${ }^{\mathrm{b}}$ \\ Elizabeth J. Parks-Stamm ${ }^{\mathrm{c}}$ \\ Derek T. Tharp ${ }^{\mathrm{d}}$
}

a Jeffrey A. DiBartolomeo is an Assistant Professor of Finance at the University of Southern Maine.

${ }^{\mathrm{b}}$ Michael G. Kothakota is a Professor of Practice at Kansas State University.

${ }^{\mathrm{c}}$ Elizabeth J. Parks-Stamm is a Part-Time Assistant Professor of Psychology at the University of Southern Maine.

${ }^{\mathrm{d}}$ Direct all correspondence to Derek T. Tharp (derek.tharp@maine.edu). Derek is an Assistant Professor of Finance at the University of Southern Maine. 


\begin{abstract}
This study investigates whether racial animosity across metropolitan markets is associated with Black financial advisor underrepresentation. Using a dataset of all U.S. securities-licensed individuals $(N=642,543)$, we first estimate the racial and ethnic composition of the industry using an algorithm that accounts for name, gender, and location. Second, we use a dataset enhanced by a commercial vendor to restrict the analysis to only those identified as working as financial advisors $(n=237,435)$. Using racially charged Google search queries as a proxy for racial animosity, we find that greater racial animosity is associated with greater Black advisor underrepresentation. We estimate lower underrepresentation of 0.9 percentage points when comparing markets with the highest and lowest levels of animosity. For the average market with an estimated $11.4 \%$ Black advisor representation, an increase of 0.9 percentage points would represent a $7.9 \%$ increase in Black advisor representation.
\end{abstract}

Keywords: Racial attitudes, racial bias, discrimination, financial advisors, underrepresentation

JEL Codes: J71, N22 


\section{Introduction}

Black financial advisors are underrepresented within the financial advisory industry (Mohrman-Gillis, 2018). However, estimates regarding the degree of underrepresentation are inconsistent. Despite accounting for $13.4 \%$ of the U.S. population, 2019 statistics released by the CFP Board suggest that about $1.6 \%^{1}$ of CERTIFIED FINANCIAL PLANNER ${ }^{\mathrm{TM}}$ professionals are Black (Salinger 2020). However, CFP® professionals are not representative of the industry as a whole, and prior research has suggested that Black and Latino advisors, in particular, may lack awareness of the $\mathrm{CFP} \circledast$ certification process and/or may face additional barriers to becoming CFP® professionals (CFP Board Center for Financial Planning 2018). 2019 data from the Bureau of Labor Statistics (BLS) estimates that Blacks make up 6.9\% of "personal financial advisors" (Bureau of Labor Statistics 2020), but BLS's expansive definition of “personal financial advisor" includes an estimated 551,000 people in the United States - a number that far exceeds industry estimates of the actual number of retail financial advisors in the United States (e.g., Cerulli Associates estimate that there were 311,305 financial advisors in the U.S. as of 2017; Fazzi 2018). Using data from the American Community Survey Public Use Microdata Sample that also appears to overestimate the number of personal financial advisors in the U.S. (i.e., 353,000 in 2018), Data USA (n.d.) estimated that between $4.7 \%$ and $6.7 \%$ of personal financial advisors were Black. Although inexact, these prior estimates suggest that the representation of Blacks in personal financial advising is approximately one-third to one-half of what would be expected given their proportion of the population.

This study therefore seeks to provide a unique estimate of the degree to which Blacks are underrepresented in the financial advisory industry based on individual-level racial and ethnic

\footnotetext{
${ }^{1}$ 1,355 reported Black CFP® professionals divided by estimated 87,000 CFP® professionals.
} 
classification estimates for every individual within the industry. We estimate the racial and ethnic composition of the financial advisory industry using the classification algorithm of Imai and Khanna (2016) applied to a dataset of all securities-licensed individuals in the United States in $2020(N=642,543)$. Unlike prior estimates, the classification algorithm we use provides unique racial and ethnic estimates for each individual licensed within the industry based on their name, gender, and location. Furthermore, we use a dataset enhanced by a commercial vendor to include job role classifications, which allows us to estimate the racial composition among those specifically identified as client-facing financial advisors $(n=237,435) .^{2}$

A second aim of the present study is to examine the relationship between local (marketlevel) racial animus towards Blacks and Black advisor underrepresentation within U.S. metropolitan markets. As noted by Reiter (2020), research on racial consumer discrimination of financial advisors is limited and accurate measures of discrimination are hard to obtain. Consumers typically do not honestly state racial preferences or prejudices in consumer surveys (e.g., Britton 2014; Prudential n.d.). Reiter (2020) found that despite White and Black consumers perceiving themselves as more similar to White and Black advisors, respectively, consumers did not express racial preferences regarding advisors they would hire, take advice from, or trust. Additionally, when asked explicitly for their attitudes, White consumers rated Black advisors as more competent than White advisors (Reiter 2020). Examining consumer racial preferences via survey data is a known challenge within the discrimination literature, since respondent selfcensorship can lead to respondents concealing their true preferences (Stephens-Davidowitz

\footnotetext{
2 This estimate is lower than the leading industry estimate of 311,305 (Fazzi 2018) in large part due to conservativeness from the data vendor, Discovery Data, in classifying someone as a financial advisor or not. If someone cannot be positively identified as an advisor (e.g., through company websites, social media profiles, or other means), the individual may receive an 'unknown' classification within their dataset. Tharp et al. (in press) empirically demonstrated that limiting analyses to this more restrictive sample addresses issues that would be theoretically anticipated when overly broad classifications of 'financial advisor' are used.
} 
2014). Consistent with the notion that survey data may mask actual discriminatory behavior, using banking record data that was not dependent upon survey responses, Black et al. (2004) found that consumer behavior revealed preferences to use banks that were owned by individuals with the same racial classification. To capture racial attitudes, researchers have used other observational data, such as racially charged Google search queries, to provide more reliable indicators of racial animosity within a geographic region (Harris \& Yelowitz 2018; StephensDavidowitz 2014). In the present study, we use racially charged Google search queries to examine whether animosity toward Blacks is associated with greater underrepresentation of Black advisors within U.S. markets. We hypothesize $\left(\mathrm{H}_{1}\right)$ that animosity toward Blacks as reflected in the Google search queries will be negatively associated with representation of Black advisors within U.S. markets.

\section{Background}

Past research has identified factors that contribute to underrepresentation in different occupations. Theorizing on the cause of underrepresentation of Black lawyers in corporate law firms have focused on both the role of institutional practices and factors outside of the institution, like the pipeline problem or applicants' social networks (Wilkins \& Gulati 1996). As job seekers often use social networks in employment searches, racially segregated social networks contribute to underrepresentation in certain roles in the workplace (Stainback 2008). Research has also begun to highlight the role of the local market context in workplace representation and occupational segregation. The racial composition of a geographic region, for example, has been found to be associated with Black underrepresentation in managerial roles (Cohen \& Huffman 2007). Greater representation of minorities in the judiciary in a region is similarly associated with reduced racial occupational segregation (Garnett 2012). An important but unexplored 
feature of the local environment that could be associated with racial underrepresentation in the role of personal finance advising is racial animus.

Racial animus, as measured by Google searches using a racial epithet for Blacks, has been shown to have real world correlates, including Black mortality rates (Chae et al. 2015), birth outcomes for Black parents (Chae et al. 2018), and voting patterns. For example, the use of the "N-word" in google searches predicted President Obama's vote share controlling for the previous Democratic candidate's results, accounting for approximately 4 percentage points in the national vote (Stephens-Davidowitz 2014).

Lyons-Padilla et al. (2019) investigate differences in the rates of investment by capital allocators in funds with White and Black managers and provide three potential channels through which Black fund managers face impediments to capital raising: the pipeline problem, bias below the bar, and bias above the bar. The pipeline problem relies on the notion that Blacks (and other minority populations) may lack the social connections, interest, education, or other socioeconomic factors that their White counterparts possess and that provide entry to careers in finance. When distinguishing between funds of similarly average performance where the managers are White or Black, bias below the bar suggests that in an industry where fund managers are predominantly White, it may be a perceived as riskier to invest with a Black manager, driving capital allocators to rely on negative stereotypes towards Blacks and choose to invest in funds with White managers. Bias above the bar relies on negative stereotypes towards Blacks, as well, but instead asserts that investors are unable to adequately assess overperforming Black fund managers because they do not align with preconceived notions of fund performance under a non-White manager. 


\subsection{Potential Mechanisms for Anti-Black Animus to Reduce Black Advisor Representation}

There are at least two mechanisms through which greater animosity toward Blacks within a market could result in greater underrepresentation of Black advisors: (a) consumer discrimination, and (b) managerial discrimination. In a market with higher levels of animus toward Blacks, consumers may discriminate against Black advisors when hiring a financial advisor. Notably, this discrimination could be subtle and does not need to necessarily manifest in overt prejudice. Something as simple as a reduced likelihood of responding to marketing materials that feature a Black advisor could be sufficient for discriminatory consumer behavior to result in worse professional outcomes for Black advisors, potentially leading to Black advisors voluntarily or involuntarily leaving the industry at disproportionate rates. Furthermore, even if an individual consumer does not personally harbor racial prejudices, an environment with higher levels of racial animosity toward Blacks may lead to consumers feeling less comfortable referring friends and family to a Black advisor out of fear that their friends or family may harbor prejudices. Since referrals are an important source of growing a financial advisory practice (Kitces 2016), this is yet another way in which consumer racial discrimination could diminish professional opportunities for Black advisors and, likewise, result in greater Black advisor underrepresentation.

Managerial discrimination is a second mechanism through which higher levels of animus toward Blacks could result in a greater underrepresentation of Black advisors. If some managers harbor prejudices against Blacks, then the biased evaluations they may provide could result in reduced opportunities for Black advisors within the industry either via reduced opportunities to enter the industry or reduced opportunities to progress within the industry. Furthermore, unequal or preferential treatment within the work environment could also result in reduced professional 
outcomes for Black advisors. Madden (2009) found that managers within two large stock brokerages were disproportionately assigning better accounts to male brokers than female brokers. Such circumstances can result in a situation where even unbiased third-parties reviewing revenue production or other performance metrics may get the impression that one group of advisors is outperforming another group of advisors (and may reward those advisors with promotions or other rewards as a result), but the outcome observed is still the result of unfair treatment of the seemingly underperforming group. Madden (2009) referred to this mechanism as performance-support bias, and environments with greater animosity toward Blacks could similarly see performance-support bias favor advisors of other racial or ethnic groups.

Notably, although both consumer discrimination and managerial discrimination could operate independently of one another (i.e., either one is sufficient to result in underrepresentation), the two could operate in tandem as well. In a market where animosity toward Blacks is generally higher, both managers and consumers will be drawn from that market, and the types of biases described above could both contribute to greater Black advisor underrepresentation. Facing both consumer and managerial discrimination could result in even higher barriers for Black advisors, and it is reasonable to suspect that these barriers are more difficult to overcome in markets with greater levels of animosity towards Blacks.

Within Lyons-Padilla et al.'s (2019) framework, both consumer and managerial discrimination could serve as a barrier overcoming the pipeline problem. If consumers express greater animosity toward Black advisors, then the reduced opportunities for referrals or other social connections that lead to professional success could be seen as part of the pipeline problem. Similarly, social connections among managers - including the types of environments and social networks, schools, and community groups that managers are recruiting from—could also result 
in greater Black advisor underrepresentation as part of the pipeline problem. Likewise, bias both “above the bar" and "under the bar" from Lyons-Padilla et al.'s (2019) framework could be further exacerbated by greater levels of regional animosity toward Blacks.

\section{Methods}

\subsection{Racial Animosity}

This study employs data from several sources to estimate the racial composition of the financial advisor industry and ultimately investigate whether there is an association between the levels of racially charged Google search queries in a market area and Black advisor underrepresentation. First, we use an animosity index (Animus; Stephens-Davidowitz 2014) that measures racially charged Google search queries by metropolitan market. Stephens-Davidowitz (2014) constructed the original measure of racial animosity using Google Trends data for search queries for the N-word and its plural from 2004-2008.

As the original measure is well over a decade old at the time of this study, we create an updated measure of racial animosity by following the general methodology of StephensDavidowitz (2014) as closely as possible, with the following deviations in methodology. It should be noted, however, that the deviations in methodology do not appear to influence the results of our analysis either quantitatively or qualitatively, as we show in the next section. The primary difference in construction of the original animosity measure and our updated measure relates to the unavailability of the Google Trends API originally employed. ${ }^{3}$ StephensDavidowitz (2014) used a computer program to sample the Google Trends API 5,000 times to construct the original measure. Since we manually collect our data, the updated measure is the

\footnotetext{
${ }^{3}$ Per an email exchange with Stephens-Davidowitz, the Google Trends API as originally employed to construct the racial animosity measure is no longer available and an updated measure following the original methodology is not feasible.
} 
average $^{4}$ of three samples. ${ }^{5}$ The second difference in methodology relates to the data available via the current public-facing Google Trends website. Trends has not historically reported data for markets with very low search volume for specific queries, in this case the N-word and its plural. Stephens-Davidowitz (2014) was able to avoid this limitation and impute a search value for markets with low racially charged search queries but only with access to the API. We omit markets from our sample with unreported values from Trends. This reduces the sample from 206 with the original measure to 188 with our updated measure.

Google Trends reports a value for each geographic area on a scale of 0 to 100 by its relative search volume. To illustrate this reporting, consider the following observations from one of our samples of Trends. We obtained values of 100 and 50 for West Virginia and Colorado, respectively, for the search term "N-word+N-words," herein referred to as query. The value of 100 for West Virginia indicates that the state had the highest search volume as a proportion of its total search volume for all terms, whereas the value of 50 indicates that Colorado had half the search volume of West Virginia for query as a proportion of that state's total search volume. Within states, metropolitan markets are similarly reported.

To construct our measure of racial animosity, we begin by querying Google Trends for the 5-year period beginning January 1st, 2015 by state for query and rank the states in ascending order, starting with a rank of 1 being assigned to the state with the highest search value. We then repeat the query at the market level, recording the value as reported by Trends. To make comparisons between markets across states, we calculate a weight, $w$, for each state, $i$ as

$$
w i=\frac{R a n k i}{51}
$$

\footnotetext{
${ }^{4}$ There is little variability between samples, suggesting using the average is not a concern.

${ }^{5}$ The Google Trends website is http://trends.google.com.
} 
and a weighted animus value for each market, $j$, within each state as

$$
\text { animusj }=\operatorname{valuej}(1-w i){ }^{6}
$$

Finally, we average weighted animus $j$ over three samples for each market to arrive at our

measure.

\subsection{Market-Level Zip Code Mapping and Demographics}

Second, zip code mapping within each market is facilitated by data made freely available online by a commercial vendor. ${ }^{7}$ Third, zip code data on household incomes and race are reported by the Census Bureau's 2018 American Community Survey, which is the most recent data available for our analyses. ${ }^{8}$ We bifurcate each zip code by household income and by the proportion of households that self-identify as a certain race, either White or Black. As we would expect relatively more affluent communities to have more financial advisors, we create two measures of household affluence for each metropolitan market: one for general affluence, regardless of race (aff_gen), and one for Black households (aff_bla). Households with annual incomes greater than or equal to $\$ 100,000$ is our threshold to be considered affluent. For each market, general affluence (aff_gen) and Black affluence (aff_bla) is the proportion of total households or Black households, respectively, that meet the threshold. Fourth, we use a dataset

\footnotetext{
${ }^{6}$ The denominator in Eq. (1) includes Washington D.C. as Google Trends reports search values for Washington D.C. in addition to the 50 U.S. states. However, we could not obtain a precise search value for the Washington D.C. metropolitan market because it is reported under several other markets, so it is excluded from our market-level sample but not the state ranking. We also include Alaska in the state rankings but do not have complete data for that state, excluding it from our market-level sample, as well.

${ }^{7}$ We use the terms "metropolitan market" and "market" to refer to media markets delineated by commercial vendors for advertising purposes. Google Trends reports data by Designated Market Area (DMA). DMAs are a proprietary geographic delineation of media markets created by Nielsen Holdings plc. As our second data source, a free alternative to DMAs is the Designated Market Maps (DMMs) available from Truckads.com, which provided the requisite zip code correlations. DMMs closely mirror DMAs for advertising on tractor trailers in targeted media markets.

${ }^{8}$ We use the term "zip code" synonymously with zip code tabulation area (ZCTA). Zip codes and ZCTAs are trademarks of the U.S. Postal Service and U.S. Census Bureau, respectively. ZCTAs are designed to be aerial geographic representations of Postal Service zip codes. Per the Census Bureau, the ZCTA codes are equivalent to the zip codes for most areas, thus we use ZCTAs in mapping Census data to market data. https://www.census.gov/programs-surveys/geography/guidance/geo-areas/zctas.html
} 
prepared by a commercial vendor, Discovery Data, containing information on all securitieslicensed individuals in the United States, including information such as advisor names (first name and surname), gender, location (home zip codes), and job role classifications.

\subsection{Advisory Industry Characteristics and Racial Composition Estimates}

Fourth, we determine the racial composition of advisors in each market area. To determine the racial composition of the advisory industry within each metropolitan market, we first use job classifications to identify and exclude those in the advisory industry without the classification of "advisor." Using the R statistical package "wru”, we then employ an extended Bayesian algorithm to predict an individual advisor's race conditional on first name, surname, gender, and zip code (Imai \& Khanna 2016). The algorithm is “extended" because a previous algorithm used in healthcare used only surnames and geolocation (Elliot, et al. 2009). Imai and Khanna (2016) used this method on voter data to determine the racial composition of voters in a particular district, by using Census data containing race, first name, surname, gender and zip code. Within the voter record data, the false positive rate for identifying an individual as Black using these parameters in the algorithm is $2.9 \%$.

We apply the same approach on our advisor dataset. Conditional on first name, surname, gender, we estimate the racial composition of a given market area. The proportion of households in each market that are White (prop_whi) or Black (prop_bla) is determined from the Census data and estimates of the proportion of advisors in each market that are White (propa_whi) or Black (propa_bla) as the mean probability as provided by the algorithm of a given name being assigned to either race.

Summary statistics for securities-licensed professionals are reported in Table 1. Out of 642,543 securities licensed individuals in our sample, over 237,000 (about 37\%) have the job 
classification containing "advisor." Of the approximately 237,000 financial advisors, about 80\% are male and $20 \%$ are female. Estimated racial and ethnic compositions of the full sample of securities-licensed professionals, all individuals classified as financial advisors, and additional subsamples of professionals are reported in Table 2. It should be noted that, while we report the estimated demographic composition of the advisory industry for all ethnicities given probabilities by the classification algorithm, our analysis in this paper focuses on Black representation two reasons. The first is that the measure of racial animosity we employ was originally developed with racial epithets towards Blacks. The second is that Black underrepresentation is an industry issue that has been noted (e.g., see CFP Board Center for Financial Planning 2018) but understudied from an empirical perspective. Overall, the algorithm used in this analysis estimates that $10.1 \%$ of financial advisors are Black (versus $13.4 \%$ of the U.S. population), which is consistent with other estimates of underrepresentation of Black advisors.

Summary statistics for market-level variables are reported in Table 3. The average market has a household composition of about $76 \%$ White and $11 \%$ Black $^{9}$, with approximately $26 \%$ of all households, and 1\% of Black households, being classified as affluent (annual household income of at least $\$ 100,000)$.

\section{Results}

To investigate whether racial animosity is associated with Black underrepresentation in the financial advisor industry, we estimate in Eq. (3), where for metropolitan market, $j$, the dependent variable is the proportion of Black advisors (propa_bla), and the regressors are the proportion of a market that is Black (prop_bla), general affluence (aff_gen), Black affluence

\footnotetext{
${ }^{9}$ Note that this is the average at the metropolitan market-level and it is not weighted by population. Therefore, our $10.1 \%$ estimate reported in Table 2 is a better metric for estimating overall representation within U.S. markets.
} 
(aff_bla), and racial animosity towards Blacks (Animus). Regression results estimated with OLS are reported as Model I (original measure of Animus) and Model II (updated measure of Animus) in Table 4.

$$
\text { Propa } \_b l a_{j}=\alpha+\beta 1 \text { Prop } \_b l a_{j}+\beta 2 A f f_{-} g e n_{j}+\beta 3 A f f_{-} b l a_{j}+\beta 4 \text { Animus }_{j}+\varepsilon_{j}
$$

The results from Models I and II suggest that both the proportion of Black households (prop_bla) and racial animosity toward Blacks (Aminus) have strong associations with the proportion of Black advisors (propa_bla) across our sample markets. The coefficients on prop_bla of 1.033 and 1.045 in Models I and II are statistically significant at the $1 \%$ level and indicate that for every 1 percentage point increase in the proportion of Black households, there is an approximately 1.03 and 1.05 percentage point increase in Black advisor representation, respectively. The coefficient estimates on general affluence (aff_gen) and Black affluence (aff_bla) are positive and negative, respectively, but neither is statistically significant for either Model I or II. Animus, however, is negatively associated with Black advisor representation, with an estimated coefficient of -0.007 that is significantly different from zero at the $5 \%$ level in Model I and a coefficient estimate of -0.008 , which is significant at the $1 \%$ level, in Model II with the updated measure. To put the relationship between racial animosity and Black advisor representation in economic terms, the range in animus of 1.29 for the original measure and about 0.98 for the updated measure indicates a potential increase in Black advisor representation of 0.9 and 0.8 percentage points, respectively, moving from the community with the most animosity to the least. For example, for the average metropolitan market with $11.4 \%$ Black advisors, an increase of 0.9 percentage points would represent about a $7.9 \%$ increase in Black advisor representation. Further, the results reported in Table 4, Models I and II, indicate that estimating 
Eq. (1) with our sample explains over $95 \%$ of the variation in Black advisor representation across our sample markets.

As our sample comprises 188 market areas within the contiguous 48 United States and Hawaii, results from estimating Eq. (1) with OLS as reported in Models I and II of Table 4 do not account for possible spatial correlation between geographic areas. Failing to model spatial correlations could bias standard errors downward. As illustrated in Figure 1, animosity toward Blacks is not randomly distributed around the U.S. In particular, some of the highest levels of animosity are concentrated in the Appalachian region. Therefore, in Table 4, we also examine the possibility that there is spatial correlation among the dependent variable, propa_bla, in Model III, and that the error terms are spatially correlated in Model IV. To conduct this robustness analysis, we create a contiguity spatial weight matrix with a shapefile for the markets (Sood 2016), which reduces the sample size to 187 markets due to data availability, and reestimate Eq. (1) with a generalized spatial two-stage least squares approach. Importantly, allowing for spatial correlation of the dependent variable (propa_bla) or the error terms does not quantitatively change our core results. The magnitudes of the estimated coefficients on animus of -0.008 and prop_bla of between 1.033 and 1.041 in Models III and IV, respectively, align with results in Models I and II. The estimates on animus and prop_bla are also statistically significant at conventional levels in these models. Last, we note that the Wald tests reported for Models III and IV in Table 4 suggest that we reject the hypothesis of spatial correlation in the dependent variable and error terms, respectively.

\section{Discussion}

This study makes a number of new contributions to the literature. First, we provide the first estimates of industry racial and ethnic composition that are based on a classification 
algorithm applied to each securities-licensed individual within the broader financial services industry. This process yields an estimate of $9.8 \%$ Black representation across the whole industry. Additionally, by using the enhanced dataset with job classifications by industry channel, we are further able to provide some unique estimates of racial and ethnic composition across different industry channels. For instance, we estimate that Black representation is highest among administrative staff (10.3\%) and lowest among those working on trading desks $(8.3 \%)$. Furthermore, while not a particular focus for the present study, we find other racial and ethnic differences across industry channels. For example, Asian representation is highest within the area of research (9.3\%) and lowest among financial planning specialists (4.3\%). The methodology used within this study could be applied to a wide range of research questions related to the racial and ethnic composition of the financial services industry.

Second, while not a primary focus of this study, the differences observed between industry channels are broadly consistent with the findings of Tharp et al. (in press) that omitting job classifications from studies using industry regulatory data - as is commonly done in most studies of the financial services industry today - is a significant limitation that warrants closer examination in the future. For instance, although we estimate that Asians are overrepresented among securities-licensed individuals overall (6.0\% overall versus 5.5\% in the U.S. population; see U.S. Census Bureau, 2019), we estimate that Asians are underrepresented among financial advisors, specifically (4.9\% versus $5.5 \%$ in the U.S. population). This illustrates the importance of taking the steps that we did in this study to differentiate financial advisors from all other securities-licensed individuals within the industry as a whole.

Third, we find evidence that greater market-level racial animosity toward Blacks is associated with greater underrepresentation of Black financial advisors. As reported in the prior 
section, we find that this relationship is both statistically and economically significant. While we cannot speak to the precise mechanism that may result in this underrepresentation, this observed relationship is important for beginning to develop a better understanding of the many factors that may be contributing to Black underrepresentation within financial services. Interest is currently high in both public and private policies that can promote greater racial and ethnic diversity within financial services. Congressional hearings have been held examining the lack of diversity in financial services, and both the EEOC and GAO have conducted studies on racial inclusion within the financial services industry (Miller \& Tucker 2013). Private firms (e.g., Edward Jones; see Schoeff Jr. 2019) and industry organizations (e.g., CFP Board; see CFP Board of Standards 2021) have instituted policies aimed at promoting greater racial and ethnic inclusion. Yet, despite strong interest in the topic, little has been known about the primary drivers of Black underrepresentation within the financial services industry. This study finds that animosity toward Blacks may be one such factor worthy of continued investigation.

Notably, our findings — based on observational data rather than self-reported feelings — do potentially contrast with prior experimental survey work which found that White participants reported perceiving Black advisors more favorably than White advisors (Reiter 2020). While the findings of these two studies jointly do not inherently disagree (it could be the case, for instance, that White consumers perceived Black advisors more favorably than White advisors, and that Black advisors are underrepresented for some other reason), one potential explanation for the findings of both of these studies is simply that it is difficult to get consumers to reveal discriminatory attitudes when completing surveys (e.g., see Stephens-Davidowitz 2014). Our findings based on observational data are largely consistent with other past studies that have found that consumers do appear to behave in ways that are racially motivated in a financial 
services context (Black et al. 2004), and that observational data is a more reliable indicator of racial animosity than survey research due to bias such as social desirability and self-censoring (Harris \& Yelowitz 2018; Stephens-Davidowitz 2014).

From a managerial perspective, firms that are interested in promoting diversity, equity, and inclusion may want to consider the additional barriers that Black advisors may face in not only markets generally, but particularly markets with greater levels of racial animus toward Blacks. While we cannot speak to the precise mechanisms resulting in the relationships observed within this study, firms may wish to be particularly cognizant of both managerial and consumer bias. Similar to combatting the gender-based performance-support bias noted by Madden (2012) within stock brokerages, firms may want to institute policies that ensure equal opportunity exists for anyone within the firm to succeed regardless of race. For instance, clear policies related to the equitable distribution of orphaned accounts (i.e., accounts that no longer have a lead advisor appointed to them due to the departure of the previous lead advisor) are one particular solution that can help ensure that managers are not acting upon potential prejudices when assigning orphaned accounts. Furthermore, from a business development perspective, firms may wish to acknowledge that an equal distribution of resources does not necessarily guarantee equal opportunity for success. For instance, if consumers are discriminating based on race, then we may expect, ex ante, that a White advisor and Black advisor who are otherwise equal in all other ways may not get the same outcome from an equal marketing budget. Firms that want to create a more even playing field for advisors may want to consider policies that could be instituted to do so.

There are a number of limitations within the existing study. First, any classification algorithm is going to be imperfect. While the algorithm used within this study has been shown to 
perform well in prior contexts, there could be something unique about applying the algorithm within this specific context that makes it more or less prone to error. Our overall estimate of Black advisor representation (10.1\%) is significantly higher than other estimates (e.g., see the BLS estimate of 6.9\%; Bureau of Labor Statistics, 2020). It is unclear at this time whether our method is overestimating or whether alternative methods are underestimating, but our estimate is, to the best of our knowledge, the first estimate that is actually based on the underlying name, gender, and location of all individuals within the industry. Second, as noted previously, our analysis cannot speak to the actual mechanism that is potentially driving the relationship between animus toward Blacks and Black advisor underrepresentation. We suspect that both managerial and consumer discrimination warrant further investigation, but that question is beyond the scope of this paper. Future studies that investigate these mechanisms more precisely may be valuable to understanding what is driving the observed relationship between animus toward Blacks and Black advisor underrepresentation. Third, as described in our methods section, we could not replicate Stephens-Davidowitz (2014) method of querying Google's data 5,000 times. Nonetheless, our measure remained strongly correlated with the dated measure from StephensDavidowitz (2014), and our findings were robust to using both our current measure and Stephens-Davidowitz's (2014) original measure. Fourth, this analysis is based solely on a snapshot from one point in time (2020) in the financial advisory industry. Future studies that can examine how animosity toward Blacks and Black advisor underrepresentation change over time may be better able to move closer toward identifying a causal relationship between these factors.

\section{Conclusion}

While the approach we take in this study does not allow us to identify the channel through which Blacks are underrepresented in the advisory industry, we report compelling 
evidence suggesting that Blacks are underrepresented by non-negligible margin. The algorithm used in this analysis estimates that $10.1 \%$ of the financial advisory industry is Black (relative to $13.4 \%$ of the U.S. population). Furthermore, our results suggest market-level racial animosity toward Blacks is negatively associated with Black advisor representation. As noted above, the underrepresentation associated with racial animosity is not trivial in economic terms.

While this analysis cannot speak to direct causal relationships between an area's racial animosity toward Blacks and Black advisor underrepresentation, we believe both consumer discrimination and managerial discrimination are two potential contributors that warrant further examination. In contrast to prior survey research that did not find evidence of consumer discrimination (e.g., Reiter, 2020), the results of our analysis using an unobtrusive measure of racial animosity and actual representation are consistent with consumer discrimination against Black advisors. Furthermore, managerial discrimination in hiring and firing of financial advisors is another potential mechanism which could contribute to underrepresentation of Black advisors and warrants further investigation.

Given the efforts to address the problem of underrepresentation of Black advisors within the financial advisory industry (CFP Board Center for Financial Planning 2018), these findings may also suggest the problem may ultimately need to be addressed at the market or societal level. Attitudes of racial prejudice in areas may make it more difficult for stakeholders in the field to combat underrepresentation of Black advisors. Policymakers and other community members may need to incorporate strategies to positively influence their market areas away from racial prejudices. 


\section{References}

Black, H. A., Robinson, B. L., Schlottmann, A. M., \& Schweitzer, R. L. (2003). Is race an important factor in bank-customer preferences? The case of mortgage lending. The Journal of Real Estate Finance and Economics, 26(1), 5-26.

Britton, D. (2014). Minority clients want culturally diverse advisory firms. Retrieved from https://www.wealthmanagement.com/prospecting/minority-clients-want-culturallydiverse-advisory-firms

Bureau of Labor Statistics. (2020, January 22). Employed persons by detailed occupation, sex, race, and Hispanic or Latino ethnicity. Retrieved from https://www.bls.gov/cps/cpsaat11.htm

CFP Board Center for Financial Planning. (2018). Racial diversity in financial planning: Where we are and where we must go. Retrieved from https://www.cfp.net/-/media/files/cfpboard/knowledge/reports-and-research/racial-diversity-in-financial-planning/racialdiversity-in-financial-planning.pdf

CFP Board of Standards. (2021). CFP Board appoints Dawn Harris as Director, Diversity \& Inclusion for the Center for Financial Planning [Press release]. Retrieved from https://www.prnewswire.com/news-releases/cfp-board-appoints-dawn-harris-as-directordiversity--inclusion-for-the-center-for-financial-planning-301262274.html

Chae, D. H., Clouston, S., Hatzenbuehler, M. L., Kramer, M. R., Cooper, H. L., Wilson, S. M., ... \& Link, B. G. (2015). Association between an internet-based measure of area racism and black mortality. PloS one, 10(4), e0122963. https://doi.org/10.1371/journal.pone.0122963

Chae, D. H., Clouston, S., Martz, C. D., Hatzenbuehler, M. L., Cooper, H. L., Turpin, R., ... \& Kramer, M. R. (2018). Area racism and birth outcomes among Blacks in the United States. Social Science \& Medicine, 199, 49-55. https://doi.org/10.1016/j.socscimed.2017.04.019

Cohen, P. N., \& Huffman, M. L. (2007). Black under-representation in management across US labor markets. The Annals of the American Academy of Political and Social Science, 609(1), 181-199. https://doi.org/10.1177/0002716206296734

Data USA. (n.d.). Personal financial advisors. Retrieved from https://datausa.io/profile/soc/personal-financial-advisors

Fazzi, R. (2018, November 7). RIAs, retail clients fuel 14.9\% rise in professional managed assets. Retrieved from https://www.fa-mag.com/news/rias--retail-clients-fuel-14-9--risein-professionally-managed-assets-41788.html

Garnett, F. G. (2012). Community matters: Uncovering the societal mechanisms undergirding workplace discrimination and inequality. [Doctoral dissertation, University of Michigan]. http://hdl.handle.net/2027.42/93897

Harris, T. F., \& Yelowitz, A. (2018). Racial climate and homeownership. Journal of Housing Economics, 40, 41-72.

Imai, K., \& Khanna, K. (2016). Improving ecological inference by predicting individual ethnicity from voter registration records. Political Analysis, 263-272. 
Kitces, M. (2016, December 12). The death of referrals and the future of business development for financial advisors. Retrieved from https://www.kitces.com/blog/death-of-referralmarketing-for-financial-advisorsin-investment-news-2016-financial-performance-study/

Lyons-Padilla, S, H. R. Markus, A. Monk, S. Radhakrishna, R. Shah, N. A. Dodson IV, \& J. L. Eberhardt. (2019). Race influences professional investors' financial judgements. Proceedings of the National Academy of Sciences, 116(35), 17,225-17,230.

Madden, J. F. (2012). Performance-support bias and the gender pay gap among stockbrokers. Gender \& Society, 26(3), 488-518.

Mohrman-Gillis, M. (2018). How can you create a more inclusive profession? Journal of Financial Planning, 31(11), 33-34.

Prudential. (n.d.). A total market approach: Winning with women and multicultural consumers. Retrieved from http://www.prudential.com/media/managed/totalmarket/TotalMarketStrategy.pdf

Reiter, M. C. M. (2020). Racial and gender preferences when hiring a financial planner: An experimental design on diversity in financial planning. [Doctoral dissertation, Kansas State University]. https://hdl.handle.net/2097/40782

Salinger, T. (2020, June 3). How many Black planners? CFP Board will answer upon request. Retrieved from https://www.financial-planning.com/news/cfp-board-discloses-1-355black-financial-planners

Schoeff Jr., M. (2019, February 1). New diversity push at Edward Jones stirs up controversy. Retrieved from https://www.investmentnews.com/new-diversity-push-at-edward-jonesstirs-up-controversy-78004

Sood, G. (2016). Geographic Information on Designated Media Markets. Harvard Dataverse, V9. https://doi.org/10.7910/DVN/IVXEHT

Stainback, K. (2008). Social contacts and race/ethnic job matching. Social Forces, 87(2), 857886. https://doi.org/10.1353/sof.0.0123

Stephens-Davidowitz, S. (2014). The cost of racial animus on a black candidate: Evidence using Google search data. Journal of Public Economics, 118, 26-40.

Tharp, D. T., Camarda, J., Lee, S., de Jong, P. J. (in press). Do CFP® professionals engage in less misconduct? Exploring the importance of job classification when comparing misconduct rates among financial service professionals. Applied Economics Letters. https://doi.org/10.1080/13504851.2020.1854441

U.S. Census Bureau. (2019). ACS demographic and housing estimates. Retrieved from https://data.census.gov/cedsci/table?q=united\%20states\&g=0100000US\&tid=ACSDP5Y 2019.DP05

Wilkins, D. B. \& Gulati, G. M. (1996). Why are there so few black lawyers in corporate law firms? An institutional analysis. California Law Review, 84(3), 493-625. 
Table 1. Financial Advisor Descriptive Statistics

\begin{tabular}{|c|c|c|c|c|}
\hline \multirow[b]{2}{*}{ Measure } & \multicolumn{2}{|c|}{$\begin{array}{c}\text { Full Sample } \\
(\mathrm{N}=642,543)\end{array}$} & \multicolumn{2}{|c|}{$\begin{array}{l}\text { Financial Advisors } \\
\qquad(n=237,435)\end{array}$} \\
\hline & $n$ & $\%$ & $n$ & $\%$ \\
\hline \multicolumn{5}{|l|}{ Gender } \\
\hline Male & 474,039 & $73.8 \%$ & 189,656 & $79.9 \%$ \\
\hline Female & 168,504 & $26.2 \%$ & 47,779 & $20.1 \%$ \\
\hline \multicolumn{5}{|c|}{ Licenses and Designations } \\
\hline $\mathrm{CFP} ®$ & 64,885 & $10.1 \%$ & 42,170 & $17.8 \%$ \\
\hline Series 6 & 190,868 & $29.7 \%$ & 84,374 & $35.5 \%$ \\
\hline Series 7 & 413,360 & $64.3 \%$ & 164,278 & $69.2 \%$ \\
\hline Series 65 & 140,796 & $21.9 \%$ & 77,612 & $32.7 \%$ \\
\hline Series 66 & 174,313 & $27.1 \%$ & 87,939 & $37.0 \%$ \\
\hline Insurance Licensed & 294,756 & $45.9 \%$ & 179,995 & $75.8 \%$ \\
\hline
\end{tabular}


Table 2. Estimated Racial and Ethnic Composition Among Various Subsamples

\begin{tabular}{|c|c|c|c|c|c|c|c|c|}
\hline & $\begin{array}{l}\text { Full Sample } \\
(\mathrm{N}=576,533)\end{array}$ & $\begin{array}{c}\text { Financial } \\
\text { Advisors } \\
(n=237,435)\end{array}$ & $\begin{array}{c}\text { Insurance } \\
\text { Licensed } \\
\text { Advisors } \\
(n=237,435)\end{array}$ & $\begin{array}{c}\text { Administrative } \\
\quad \text { Staff } \\
(n=5,299)\end{array}$ & $\begin{array}{c}\text { Planning } \\
\text { Specialist } \\
(n=7,420)\end{array}$ & $\begin{array}{c}\text { Portfolio } \\
\text { Manager } \\
(n=9,677)\end{array}$ & $\begin{array}{c}\text { Research } \\
(n=10,956)\end{array}$ & $\begin{array}{c}\text { Trading Desk } \\
(n=6,696)\end{array}$ \\
\hline White & $72.9 \%$ & $74.3 \%$ & $75.2 \%$ & $73.8 \%$ & $76.5 \%$ & $76.1 \%$ & $71.6 \%$ & $73.3 \%$ \\
\hline Black & $9.8 \%$ & $10.1 \%$ & $10.2 \%$ & $10.3 \%$ & $10.0 \%$ & $9.4 \%$ & $8.8 \%$ & $8.3 \%$ \\
\hline Hispanic & $8.8 \%$ & $8.2 \%$ & $7.6 \%$ & $8.8 \%$ & $6.7 \%$ & $6.3 \%$ & $7.8 \%$ & $8.0 \%$ \\
\hline Asian & $6.0 \%$ & $4.9 \%$ & $4.5 \%$ & $4.6 \%$ & $4.3 \%$ & $5.7 \%$ & $9.3 \%$ & $7.9 \%$ \\
\hline Other & $2.5 \%$ & $2.5 \%$ & $2.5 \%$ & $2.5 \%$ & $2.5 \%$ & $2.5 \%$ & $2.5 \%$ & $2.4 \%$ \\
\hline
\end{tabular}

Notes: Groups included in the table above are not mutually exclusive. Individuals could have multiple classifications (e.g. "Financial Advisor" and "Portfolio Manager"). 
Table 3. Market-Level Variables $(n=188)$

\begin{tabular}{lrrrrr}
\hline Variable & Mean & Std. Dev. & Median & Min & Max \\
\hline Animus - original & 0.64 & 0.20 & 0.62 & 0.26 & 1.55 \\
Animus - updated & 0.43 & 0.24 & 0.43 & $>0.00$ & 0.98 \\
Proportion White (prop_whi,\%) & 75.53 & 9.63 & 77.14 & 14.33 & 86.83 \\
Proportion Black (prop_bla, \%) & 11.45 & 3.50 & 10.47 & 2.03 & 20.63 \\
$\begin{array}{l}\text { Proportion of White Advisors } \\
\text { (propa_whi, \%) }\end{array}$ & 76.53 & 9.00 & 77.95 & 14.52 & 87.00 \\
$\begin{array}{l}\text { Proportion of Black Advisors } \\
\text { (propa_bla,\%) }\end{array}$ & 11.44 & 3.60 & 10.37 & 1.89 & 21.56 \\
General Affluence (aff_gen, \%) & 26.02 & 8.19 & 24.43 & 12.71 & 53.42 \\
Black Affluence (aff_bla,\%) & 1.07 & 1.15 & 0.73 & 0.00 & 7.60
\end{tabular}

Notes: Affluence is defined as household income of $\$ 100,000$ or greater. 
Table 4. Regression Results Predicting Black Advisor Representation

\begin{tabular}{|c|c|c|c|c|}
\hline Model & I & II & III & IV \\
\hline Intercept & $\begin{array}{l}0.001 \\
(0.25)\end{array}$ & $\begin{array}{l}-0.002 \\
(-0.45)\end{array}$ & $\begin{array}{l}-0.002 \\
(-0.47)\end{array}$ & $\begin{array}{l}-0.001 \\
(-0.48)\end{array}$ \\
\hline Animus & $\begin{array}{c}-0.007^{* *} \\
(-2.26)\end{array}$ & $\begin{array}{c}-0.008^{* * *} \\
(-2.66)\end{array}$ & $\begin{array}{c}-0.008^{* * *} \\
(-2.67)\end{array}$ & $\begin{array}{c}-0.008^{* *} \\
(-2.57)\end{array}$ \\
\hline Prop_bla & $\begin{array}{l}1.033^{* * *} \\
(47.29)\end{array}$ & $\begin{array}{l}1.045^{* * *} \\
(45.84)\end{array}$ & $\begin{array}{l}1.033^{* * *} \\
(39.52)\end{array}$ & $\begin{array}{c}1.041^{* * *} \\
(46.19)\end{array}$ \\
\hline Aff_gen & $\begin{array}{l}0.002 \\
(0.25)\end{array}$ & $\begin{array}{l}0.001 \\
(0.13)\end{array}$ & $\begin{array}{l}0.001 \\
(0.11)\end{array}$ & $\begin{array}{l}0.002 \\
(0.21)\end{array}$ \\
\hline Aff_bla & $\begin{array}{l}-0.082 \\
(-1.22)\end{array}$ & $\begin{array}{l}-0.052 \\
(-0.77)\end{array}$ & $\begin{array}{l}-0.043 \\
(-0.65)\end{array}$ & $\begin{array}{l}-0.045 \\
(-0.67)\end{array}$ \\
\hline $\mathrm{N}$ & 188 & 188 & 187 & 187 \\
\hline $\begin{array}{l}\text { Adj. } R^{2} / \\
\text { pseudo } R^{2}\end{array}$ & $95.40 \%$ & $95.45 \%$ & $95.74 \%$ & $95.73 \%$ \\
\hline$F($ d.f. $)$ & $971.2(183)$ & $981.6(183)$ & & \\
\hline $\begin{array}{l}\text { Wald } X^{2} \\
\text { statistic } \\
(p \text {-value })\end{array}$ & & & $\begin{array}{c}0.51 \\
(0.474)\end{array}$ & $\begin{array}{c}0.16 \\
(0.690)\end{array}$ \\
\hline \multicolumn{5}{|c|}{$\begin{array}{l}\text { Notes: Model I is estimated with OLS and the original measure of animosity. Models II-IV } \\
\text { employ the revised animosity measure and are estimated with OLS (II) or generalized spatial } \\
\text { 2SLS with spatial dependence of the dependent variable (III) or the error term (IV). Adjusted } \\
\mathrm{R}^{2} \text { is reported for OLS models, while pseudo } \mathrm{R}^{2} \text { is reported for spatial } 2 \text { SLS models. } t \text {-statistics } \\
\text { are reported in parentheses. Statistical significance at the } 1 \%, 5 \% \text {, and } 10 \% \text { levels are denoted } \\
* * * * * * \text { and }{ }^{*} \text {, respectively. }\end{array}$} \\
\hline
\end{tabular}


Figure 1. Geographic Variation in Racial Animosity Toward Blacks

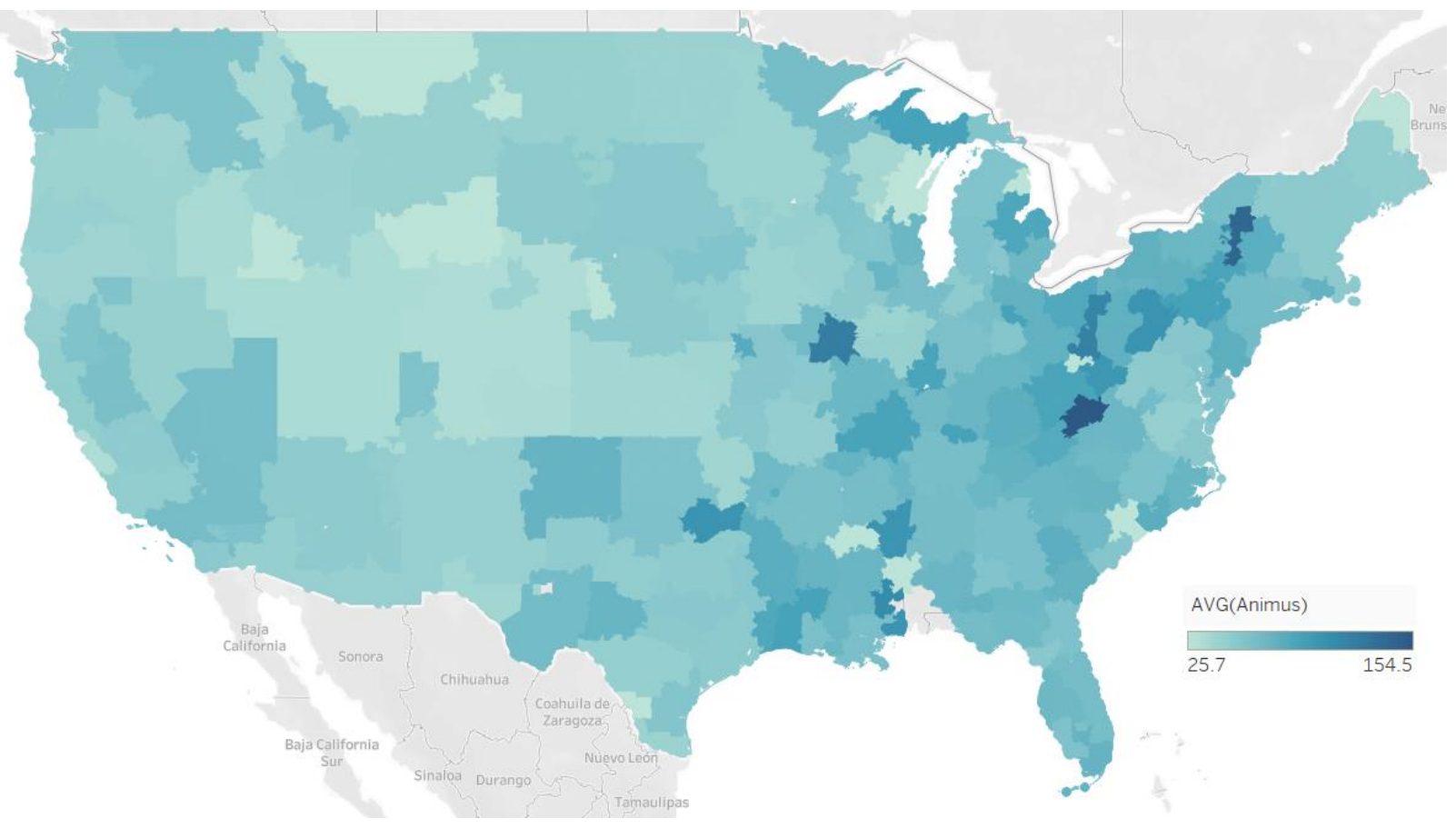

Note: Darker blue indicates greater levels of racial animosity toward Blacks. 